\title{
Discriminação e Racismo na União Europeia: diagnóstico de uma ameaça negligenciada e da investigação científica correspondente
}

LUDGER PRIES*

NATALIA BEKASSOW

\section{Resumo}

Manifestações semanais do controverso movimento PEGIDA (Europeus Patriotas contra a Islamização do Ocidente) estavam ganhando popularidade em diversas cidades alemãs entre o final de 2014 e o final do mês de janeiro de 2015. Os assassinatos ocorridos na sede da revista satírica Charlie Hebdo e no supermercado Hyper Cacher durante a segunda semana de janeiro revelaram a realidade do antissemitismo e provocaram surtos de islamofobia em muitos países europeus. Discriminação e racismo são, evidentemente, questões importantes na Europa. Mas que significado têm esses eventos? Quão disseminadas são a discriminação e o racismo na Europa? Este artigo descreve, inicialmente, os antecedentes históricos e o desenvolvimento de um marco formal Europeu para não discriminação, em seus aspectos institucionais e jurídicos. Em seguida, apresenta e discute as principais fontes de dados oficiais e científicas para o estudo da discriminação na União Europeia. Depois, aborda a situação atual do racismo e da discriminação na EU, com base nos estudos mais recentes e abrangentes sobre o tema. Finalmente, são esboçadas algumas tendências e desafios para novas pesquisas na área.

Palavras-chave: Discriminação. Racismo. Europa. Políticas de não-discriminação.

\footnotetext{
* Ruhr-Universität Bochum (Alemanha)

** Ruhr-Universität Bochum (Alemanha)
} 
Sociologias, Porto Alegre, ano 17, no 40, set/dez 2015, p. 176-211

\section{Discrimination and Racism in the European Union: diagnostic of a neglected challenge and the corresponding scientific research ${ }^{* * *}$}

\section{Abstract}

Weekly demonstrations of the controversial PEGIDA movement (Patriotic Europeans Against the Islamization of the Occident) were gaining in popularity in different German cities during end of 2014 until end of January 2015. Deaths at the offices of satirical magazine Charlie Hebdo and the murdering at Hyper Cacher, a Jewish supermarket, during the second week of January 2015 revealed the reality of Antisemitism and led to higher levels of Islamophobia in many European countries. Obviously discrimination and racism are important issues in Europe. But what do these events stand for? How extended are discrimination and racism in Europe? In this article, first the historical background and development of the European formal non-discrimination framework in its legal and institutional aspects is described. Then the most important official and scientific data sources for studying discrimination in the EU are presented and discussed. After that the current situation of racism and discrimination in the EU is presented based on the most recent and comprehensive related studies. Finally, some trends and challenges for further research will be outlined.

Key words: Discrimination. Racism. Europe. Anti-discrimination policies

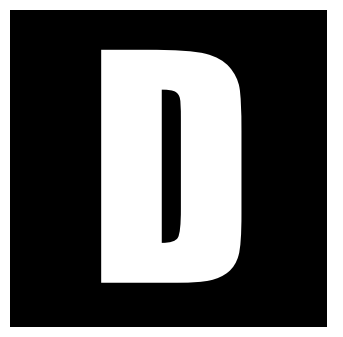

esde o final de 2014, manifestações semanais do controverso movimento PEGIDA ${ }^{1}$ (Europeus Patriotas contra a Islamização do Ocidente) ganhavam popularidade em diversas cidades, especialmente em Dresden, com mais de dez mil participantes até o final de janeiro de 2015. As cidades do lado ocidental da Alemanha contavam com menos de mil participantes nas manifestações do PEGIDA e sempre com um

\footnotetext{
${ }^{1}$ Sigla do alemão Patriotische Europäer Gegen die Islamisierung des Abendlandes. N.T.

*** Tradução: Luna Traduções e Comunicação. Revisão Técnica: Karl Monsma
} 
número muito maior de pessoas protestando contra esse. Mas, sem dúvida, o referido movimento levou o tema do racismo, da islamofobia e do antissemitismo ao centro dos debates públicos. Ninguém poderia esperar tal ressonância, quando cerca de 350 pessoas se reuniram para participar da chamada "caminhada do entardecer", em 20 de outubro de 2014, em Dresden. O mais inquietante é que, ao contrário do 'Hooligans contra Salafis' ('HoGeSa'), outra série de manifestações islamofóbicas no início deste ano, o PEGIDA logrou tornar-se atrativo não só para as atividades da ultradireita, como também para os cidadãos e as cidadãs comuns chamados "cidadãos preocupados".

A maioria dos políticos mais importantes da Alemanha foi convergente em sua reação: o Ministro da Imigração, Aydan Özoguz, condenou os protestos Pegida; o Ministro da Justiça, Heiko Maas (SPD), os chamou de 'hipócritas' e falou sobre a 'repulsiva canibalização' das memórias das vítimas do Charlie Hebdo. O Primeiro Ministro bávaro, Horst Seehofer (CSU) clamou inclusive pela suspensão das manifestações. Mas, também, muitos políticos (de todos os partidos) argumentaram que os participantes das manifestações PEGIDA eram, na maioria, apenas 'cidadãos comuns do seio da sociedade' e que era importante escutar atentamente suas preocupações. Mesmo o vice-chanceler e presidente do partido Social Democrata, Sigmar Gabriel, compareceu à manifestação de 23 de janeiro de 2015, para falar com os seguidores do Pegida².

Os disparos na sede da revista satírica Charlie Hebdo e os assassinatos no Hypercacher, um supermercado de produtos kosher, durante a segunda semana de janeiro de 2015, tiveram por primeiro efeito justamente agregar argumentos à retórica islamofóbica do PEGIDA. Segundo

\footnotetext{
${ }^{2} \mathrm{http} / / / \mathrm{www}$.spiegel.de/politik/deutschland/pegida-sigmar-gabriel-diskutiertin-dresden-mit-anhaengern-a-1014783.html.
} 
o movimento, 'o ocidente' (uma construção social de alguns grupos sociais do 'ocidente') é caracterizado por valores cristãos, e 'o Islã' (assim como, para muitos seguidores do Pegida, os 'os judeus') está ameaçando a coesão social das sociedades do 'ocidente' ao pedir demais aos 'cidadãos comuns'.

No entanto, o relatório anual sobre imigração do Departamento Federal de Imigração e Refugiados, apresentado em 21 de janeiro de 2015 pelo Ministro do Interior, Thomas de Maizière, contradiz essas 'preocupações dos cidadãos comuns' (que em geral são, na verdade, inquietações daqueles que se escondem sob o papel de porta-vozes do 'povo'). A imigração para a Alemanha é predominantemente europeia. Em 2013, 58\% de todos os imigrantes que ingressaram no país vinha de países da Europa. O principal país de origem - desde 1996 - é a Polônia. Em 2013, ocorreu um crescimento significativo do número de imigrantes vindos da Romênia e da Bulgária (tendência evidente e continuada desde o ingresso desses países na União Europeia, em 2007), bem como da Croácia, Espanha e Itália (BAMF, 2015:245). A proporção de muçulmanos em Dresden, o foco do movimento PEGIDA, é inferior a um por cento da população; para o estado da Saxônia, onde se localiza Dresden, é ainda menor, 0,1 por cento. Na Alemanha, vivem hoje cerca de duzentas mil pessoas de confissão judaica, e cerca de cem mil são consideradas membros da comunidade judaica ${ }^{3}$.

As manifestações PEGIDA na Alemanha, os ataques terroristas e antissemitas em Paris, mas também a força dos partidos nacionalistas de extrema direita, antissemitas e anti-islã, em muitos países europeus (Áustria,

\footnotetext{
${ }_{3}^{3}$ Com relação aos muçulmanos, ver http://www.spiegel.de/politik/deutschland/pegida-die-thesen-im-faktencheck-a-1008098.html e http://zentralrat.de/2597_main.php; para a Alemanha, ver http://de.wikipedia.org/wiki/Religionen_in_Deutschland, com relação aos judeus, ver BAMF 2015: 113; http://www.amadeu-antonio-stiftung.de/aktuelles/antisemitismus-in-deutschland-ein-lagebild-2015/and http://www.zentralratdjuden.de/de/topic/5.mitglieder.html
} 
Dinamarca, França, Grécia, Itália, Holanda, Noruega, Suécia, Suíça), bem como em muitos dos países da Europa oriental que recentemente ingressaram na União Europeia (UE) (como Bulgária, Hungria, Polônia e Romênia) representam graves ameaças à UE e sua promessa de ser uma "Área de liberdade, segurança e justiça" ${ }^{4}$. Embora a União Europeia disponha de um marco jurídico e institucional altamente desenvolvido contra o racismo, a realidade social parece diferir das promessas. Em vários países da UE, persistem antigas tradições racistas (como contra os ciganos, ou roma, na Bulgária, Hungria, Romênia e muitos outros países da UE); alguns países experimentaram ondas de racismo violento de extrema direita (como as ocorridas em Solingen ou Mölln, na Alemanha, durante os anos 1990, ou na Grécia, durante a última década).

Podem-se levantar várias questões: por que o racismo é tão forte em suas diferentes manifestações? O que influencia as várias ondas de diferentes formas de discriminação (do antissemitismo ao anti-islamismo e a círculos viciosos de ambos)? Quão efetiva e eficiente é a política da UE para combater o racismo? Quais os principais resultados da pesquisa científica sobre discriminação e racismo na UE? Não há espaço, neste artigo, para tratar de todas essas questões. As próximas seções irão concentrar-se em um balanço da produção científica sobre a extensão, formas e trajetória do racismo na UE: Quais são as principais formas de discriminação e racismo observadas nos estados membros da UE? Há tendências evidentes de crescimento ou redução dos incidentes de discriminação e racismo? O que de fato sabemos sobre a magnitude da discriminação e do racismo na Europa, e que tipo de dados está disponível? Os conceitos de discriminação e racismo utilizados pelos estados membros da UE são os mesmos, de modo a permitir a comparação de dados? Existe uma abordagem ou marco especificamente europeu para lidar com questões de discriminação e racismo?

${ }^{4}$ Ver http://free-group.eu/texts. 
Assim, serão descritos os antecedentes históricos e os avanços do arcabouço antidiscriminação formal europeu em seus aspectos jurídicos e institucionais (seção um). Em seguida, as fontes de dados oficiais e científicas mais importantes para o estudo da discriminação na União Europeia são apresentadas e discutidas (seção dois). Depois disso, será introduzida a situação atual do racismo e da discriminação na UE, com base nos estudos mais recentes e abrangentes relacionados ao tema (seção três). Finalmente, serão esboçadas algumas tendências e desafios para futuras pesquisas (seção quatro).

\section{Antecedentes históricos: da discriminação ao Holocausto}

Quando se trata de discriminação na Europa, há que distinguir uma dimensão jurídica e uma social. Em seu sentido original, a palavra latina discriminare significa separar, diferenciar ou distinguir. Em várias línguas, o termo discriminação - derivado do Latim e usado no sentido de uma discriminação social (positiva ou negativa) - significa negar sistematicamente, a indivíduos ou grupos sociais, as mesmas oportunidades conferidas a outros, em razão de características adscritas específicas relacionadas àqueles, como cor da pele, raça, etnicidade, origem nacional, língua, crenças políticas ou religiosas, gênero, orientação sexual, idade, ou alteridade ou limitação física ou mental. Em termos jurídicos, existem diferentes mecanismos para favorecer ou desfavorecer determinados grupos de pessoas. Um nível básico de discriminação positiva é a cidadania em um determinado Estado. A cidadania oferece uma série de privilégios (como o direito de residência no território do estado, acesso ao mercado de trabalho e à seguridade social básica, direito de voto e de ser eleito, direito a propriedade), mas também envolve uma série de obrigações (como educação escolar compulsória, serviço militar, obrigação de votar). A dis- 
criminação positiva também se refere ao uso gratuito (ou mediante tarifas reduzidas) de serviços públicos como museus ou serviços de transporte para determinados grupos etários (estudantes ou pessoas aposentadas) ou áreas especiais para mulheres e crianças em estações de metrô.

Para os propósitos deste artigo, interessa a discriminação social negativa. Sob a perspectiva sociológica, a própria existência de dispositivos jurídicos de discriminação positiva reflete o fato de que certos grupos sociais precisam ser protegidos formalmente de modo específico, porque, do contrário, a discriminação social negativa incidente sobre eles seria ainda mais forte. Segundo esta lógica, mulheres e crianças seriam 'marginalizadas' no uso dos metrôs, se não existisse uma zona especial que Ihes permita entrar, porque prevaleceria a regra de dominação "do mais forte". Menores de idade e idosos pensionistas são discriminados positivamente, com dispensa de taxas em museus ou piscinas públicas, porque, de outro modo, seriam excluídos ou discriminados no uso desses serviços, em razão de seus escassos recursos econômicos.

Visto de uma perspectiva sociológica de desigualdade social (Pries, 2014, capítulo 12; ver também Lamont/Mizrachi, 2012: 367 e s.), o processo social de discriminação envolve quatro precondições. Primeira, o acesso a recursos socialmente escassos e desejados (bens econômicos como propriedades, renda ou alimentos saudáveis; bens públicos como educação, saúde, ar puro; relações, confiança e redes sociais, reconhecimento e atenção) é restringido por certos mecanismos sociais de inclusão e exclusão de indivíduos e grupos, e esses recursos são desigualmente distribuídos entre os membros da entidade social em questão (um âmbito de interação como uma comunidade, uma organização, uma nação ou a 'sociedade mundial'). Segunda, há competição, conflitos e lutas sociais entre indivíduos e grupos, com relação aos direitos de uso e distribuição desses recursos demandados e limitados. Terceira, o mecanismo social de 
distribuição do acesso a esses recursos não foi acordado entre os membros da unidade social em questão (como nos jogos, em que todos os participantes precisam pactuar as regras desde o início), mas é definido por um grupo social hegemônico ou dominante. Quarta, esse grupo central poderoso logra definir a atribuição social de certos direitos e status na competição por recursos desejados, segundo camadas grupais que não são negociadas ou acordadas entre os grupos envolvidos.

Com base nessas precondições, discriminação pode ser definida como a percepção e tratamento sistematicamente distintos e hierarquicamente valorativos (positiva ou negativamente) de pessoas, com base não em suas características reais, mas em estereótipos atribuídos a um determinado grupo social formado de estratos como gênero, idade, cor da pele, religião, cultura ou (supostas) limitações físicas ou mentais. Assim, racismo poderia ser entendido como uma forma específica de discriminação baseada em aspectos visíveis da distinção social (Lentin 2004, pp. 72 e s.; Weiß, 2013, pp. 24 e s.), embora o termo raça tenha experimentado uma mudança importante em seus fundamentos, que passaram de biológicos para culturais (sobre esta mudança nas Nações Unidas ver, por ex., Müller, 2014).

Um bom exemplo do processo de discriminação pode ser encontrado no estudo "Os estabelecidos e os Outsiders", de Norbert Elias e John L. Scottson. Em seu estudo de uma pequena vila de trabalhadores inglesa, eles mostram como famílias estabelecidas unem-se e definem a si mesmas como superiores aos recém chegados, concentrados em áreas específicas da vila - embora não existam diferenças significativas entre os grupos no que se refere ao nível ocupacional, estrutura etária, língua, nacionalidade, etnicidade etc. Os outsiders internalizam e reproduzem, em certa medida, sua posição marginalizada, atribuída simplesmente por mecanismos de relações de poder, e não por meritocracia ou outros aspectos qualitativos que pudessem justificar tal bifurcação no estatuto social designado 
a cada grupo. Por causa de sua origem judia, Norbert Elias precisou fugir do regime nazista da Alemanha, o qual, sem dúvida, estabeleceu o mais brutal sistema de discriminação já visto na história humana.

Já em 1933, o ano em que o regime nazista assumiu o poder, foi promulgada a Lei de Revogação das Naturalizações e Negativa de Cidadania Alemã, a qual declarava que: "as naturalizações concedidas entre 9 de novembro de 1918 e 30 de janeiro de 1933 podem ser revogadas se a naturalização for considerada indesejável" (Göktürk et al. 2011: 155). Essa lei já denunciava o caráter ditatorial e desumano do regime nazista, ao transformar a cidadania, de um direito individual a uma decisão estatal por conveniência. Além disso, ela já definia o rumo da política nazista de discriminação: "Doravante, serão passíveis de revogação da naturalização: a. os judeus orientais, a menos que tenham lutado no front alemão durante a guerra mundial ou se tenham mostrado particularmente úteis aos interesses alemães; b. Pessoas responsáveis por crimes ou delitos graves, ou que tenham praticado outros atos prejudiciais ao Estado e ao Povo (Volk)" (ibid: 155).

De modo simbólico, exatamente um ano após tomar o poder na Alemanha, em 30 de janeiro de 1934, o regime nazista promulgou a Lei de Reconstrução do Império de 1934, introduzindo a noção de cidadania comum alemã, a qual, segundo a ideologia nazista, constituiria o apogeu do processo milenar de formação do 'Reich Alemão' desde Carlos Magno. Contudo, essa ideia de uma cidadania alemã generalizada já havia sido rompida pela Lei de Revogação das Naturalizações e Negativa de Cidadania Alemã de 1933. E apenas um ano mais tarde (com a Lei do Cidadão Imperial, de 15 de novembro de 1935), a categoria de 'cidadania alemã' enquanto pertencente ao estado alemão como residente ou como natural do país (Staatsangehörigkeit) foi substituída por um conceito de ser 'cidadão na Alemanha' com diferentes condições e direitos. Durante os anos seguintes, essa diferenciação utilitarista, racial e política da cidadania conduziu às categorias resumidas na Tabela 1. 
Tabela 1. Categorias de cidadania durante o regime nazista na Alemanha

\begin{tabular}{|c|c|c|}
\hline Categoria & Definição & Direitos/ obrigações \\
\hline $\begin{array}{l}\text { Reichsbürger } \\
\text { ('cidadão do Reich') }\end{array}$ & $\begin{array}{l}\text { 'de sangue alemão ou relacio- } \\
\text { nado, disposto a, e capaz de } \\
\text { servir ao povo e ao Império } \\
\text { Alemão'. }\end{array}$ & $\begin{array}{l}\text { Os únicos com direitos e obri- } \\
\text { gações políticas oficialmente } \\
\text { plenos (embora ainda bastante } \\
\text { limitados) }\end{array}$ \\
\hline $\begin{array}{l}\text { Staatsangehöriger } \\
\text { (pessoa nacional) }\end{array}$ & $\begin{array}{l}\text { 'pertencentes à unidade de } \\
\text { proteção do Império Alemão' } \\
\text { (Schutzverband des Deutschen } \\
\text { Reiches) e, portanto, submeti- } \\
\text { dos a esta; 'cidadãos comuns' }\end{array}$ & $\begin{array}{l}\text { Comparados com os cidadãos } \\
\text { do Reich, direitos e proteção } \\
\text { formais ainda mais limitados }\end{array}$ \\
\hline $\begin{array}{l}\text { Staatsangehörige auf } \\
\text { Widerruf (cidadãos } \\
\text { até revogação) }\end{array}$ & $\begin{array}{l}\text { O regime nazista poderia con- } \\
\text { ceder o status de ,cidadão até } \\
\text { revogação' para grupos especi- } \\
\text { ais; o status poderia ser revoga- } \\
\text { do em um prazo de dez anos, } \\
\text { por exemplo, quando o proces- } \\
\text { so de ,germazinação' não resul- } \\
\text { tasse efetivo. }\end{array}$ & $\begin{array}{l}\text { Comparados aos cidadãos do } \\
\text { Reich: submetidos a discrimina- } \\
\text { ção social e a desvantagens de } \\
\text { ordem judicial }\end{array}$ \\
\hline $\begin{array}{l}\text { Schutzangehörige } \\
\text { (pertencentes à area } \\
\text { de proteção) }\end{array}$ & $\begin{array}{l}\text { Pessoas não-alemãs poderiam } \\
\text { tornar-se 'Schutzangehörige' me- } \\
\text { diante resoluções gerais (,allge- } \\
\text { meine Anordnung') ou em casos } \\
\text { individuais }\end{array}$ & $\begin{array}{l}\text { Em princípio, sem direitos; o } \\
\text { status jurídico específico e os } \\
\text { direitos nunca foram definidos }\end{array}$ \\
\hline Judeus e Roma & $\begin{array}{l}\text { Pessoa com 'sangue estrangeiro' } \\
\text { ('artfremdem Blut'); Judeu: uma } \\
\text { pessoa que descende de pelo } \\
\text { menos três avós judeus; Judeu } \\
\text { miscigenado ('Mischling'): des- } \\
\text { cendente de pelo menos um } \\
\text { ou dois avós judeus (avós que } \\
\text { professam a crença judaica são } \\
\text { considerados judeus) }\end{array}$ & $\begin{array}{l}\text { Sem direitos políticos e prote- } \\
\text { ção legal; discriminados social, } \\
\text { econômica e politicamente; por } \\
\text { ex. casamentos com alemães e } \\
\text { quaisquer outras relações fami- } \\
\text { liares inter-raciais são proibidas; } \\
\text { poderiam ser colocados sob } \\
\text { 'custódia protetiva' ou serem } \\
\text { deportados para campos de } \\
\text { concentração a qualquer mo- } \\
\text { mento. }\end{array}$ \\
\hline
\end{tabular}

Fonte: Elaboração própria com base em Münch, 2007, pp. 61-73; Gosewinkel, 2001, pp. 369-420 e Gosewinkel, 2008, pp. 1-20 
Não havia uma noção estabelecida sobre o que seria ou deveria ser a nação germânica ou a cidadania germânica. Quando o regime nazista simulava 'realizar' o Império Germânico como Nação, não havia qualquer discurso público, acordo ou entendimento civil, mas simplesmente a definição racista, presunçosa e totalitarista de categorias de pertencimento ao partido e ao regime nazistas 5 . A criação dessas categorias de pertencimento foi um processo de improvisação, pragmático, oportunista, desumano e violento imposto "de cima": aqueles de 'sangue alemão' que não estavam dispostos (p.ex. comunistas e anarquistas) ou não eram capazes (p.ex. pessoas com deficiências) de 'servir ao povo alemão e ao Império' foram excluídos da categoria de 'cidadãos do Reich'. Na medida em que essas pessoas podiam ser exploradas pelo projeto nazista, elas eram 'cidadãs comuns' ou 'cidadãs até revogação' que detinham alguns direitos básicos. Estrangeiros, prisioneiros de guerra e trabalhadores forçados foram declarados 'pertencentes à área de proteção' (do Império Germânico) e só tinham 'o direito ao trabalho'. Mais tarde, judeus, roma, homossexuais, pessoas com deficiências mentais e outras foram declaradas 'indignas da vida'. Em resumo, para definir direitos de cidadania, o regime nazista não seguiu estritamente ou de modo dogmático o princípio ius sanguinis, mas aproximadamente a lógica de um ius mentis civilis (direito do patriotismo correto) ${ }^{6}$.

Esta breve referência à lógica da discriminação oficial pelo Estado, que conduziu ao assassinato de milhões de judeus, ativistas políticos de esquerda, homossexuais, pessoas com deficiências e delinquentes comuns na Alemanha e nos países ocupados, é necessária ao menos por duas razões. Primeiro, o Holocausto, mostra que a discriminação

\footnotetext{
${ }^{5}$ Para a interseção entre raça e gênero durante o regime nazista ver, por exemplo, Bock, 1984. ${ }^{6}$ Para mais detalhes sobre esse ponto ver, por exemplo, Pries, 2013b, onde a Tabela 1 e respectiva informação foram publicadas originalmente; para uma análise da diferença entre normas e políticas de jure e de facto no regime nazista, especialmente sobre o apoio ao antissemitismo nos processos jurídicos, ver, por ex. Jahr, 2011, pp. 284 e seguintes.
} 
sistemática pode resultar no assassinato de uma grande proporção da população alvo da discriminação. Segundo, quase todas as iniciativas contra a discriminação formuladas após a II Guerra Mundial pelos organismos internacionais como as Nações Unidas e, especialmente, por Estados europeus referem-se explicitamente à experiência histórica do regime nazista e do Holocausto.

\section{Desenvolvimento de um marco legal de não discriminação na Europa}

Após os feitos abomináveis da II Guerra Mundial, dez países da Europa ocidental (Bélgica, Dinamarca, França, Irlanda, Itália, Luxemburgo, Holanda, Noruega, Suécia e Reino Unido) fundaram, em 1949, o Conselho da Europa (Council of Europe - CoE) com o objetivo de promover o estado de direito, a democracia, a liberdade, os direitos humanos e o desenvolvimento social ${ }^{7}$. O Conselho da Europa adotou a Convenção Europeia de Direitos Humanos (European Convention on Human Rights $E C H R$ ) "que foi o primeiro tratado moderno de direitos humanos baseado na Declaração Universal dos Direitos Humanos das Nações Unidas" ${ }^{8}$.

Em 2014, o Conselho da Europa incluía 47 estados europeus, abrangendo uma população de 820 milhões de pessoas protegidas contra a discriminação no que concerne ao exercício de qualquer direito assegu-

\footnotetext{
${ }^{7}$ Ver http://www.echr.coe.int/Documents/Convention_ENG.pdf, Preâmbulo.

${ }^{8}$ FRA, 2010: 12; a Declaração Universal dos Direitos Humanos foi proclamada pela Assembleia Geral das Nações Unidas em 1948. Seu artigo 70 estabelece: “Todos são iguais perante a lei e têm direito, sem qualquer discriminação, a igual proteção da lei. Todos têm direito a proteção igual contra qualquer discriminação que viole a presente Declaração e contra qualquer incitamento a tal discriminação". Ver http://www.un.org/en/documents/udhr/ e http://www.ohchr. org/EN/UDHR/Pages/Introduction.aspx.
} 
rado pelos tratados firmados pelo conselho ${ }^{9}$. A Corte Europeia de Direitos Humanos foi instituída em 1959, com base no artigo 19 da ECHR, e confere a qualquer indivíduo, organização não governamental ou grupo de indivíduos, bem como a um ou mais dos estados membros a possibilidade de ingressar com uma representação contra qualquer estado membro do Conselho da Europa. Embora a jurisdição da Corte abarcasse apenas os direitos fundamentais expressos na ECHR, mais tarde estendeu-se à proibição da discriminação no tratamento substantivo de todas as pessoas: "O artigo 14. a da ECHR proíbe a discriminação apenas na medida em que a mesma esteja ligada ao exercício de um outro direito reconhecido pela Convenção, enquanto que o Protocolo no 12 à ECHR confere à discriminação um carácter autónomo" (FRA, 2010, p. 19). No contexto de racismo e discriminação, destaca-se a Comissão Europeia contra o Racismo e a Intolerância (European Commission on Racism and Intolerance - ECRI) vinculada ao $\mathrm{CoE}^{10}$. Esta comissão reúne dados e monitora a situação em todos os 47 estados membros. Este fato é importante porque seu trabalho abarca muitos países que não são membros da EU, como será discutido adiante. No entanto, não há um informe comparativo ou outro relatório semelhante integrado sobre a situação do racismo na área do Conselho da Europa. A comissão (ECRI) publica declarações e recomendações quando a situação em um dos estados membros do Conselho da Europa é crítica com relação à situação dos direitos humanos e do racismo ${ }^{11}$.

Além do sistema mais amplo, que compreende o Conselho da Europa, a Convenção Europeia de Direitos Humanos e a Corte Europeia

\footnotetext{
${ }_{9}^{9}$ Para mais detalhes ver http://www.coe.int/web/portal/home, Direitos Humanos.

${ }^{10}$ Ver http://www.coe.int/t/dghl/monitoring/ecri/default_en.asp e para os informes de monitoramento de países (para a Alemanha, por ex., há cinco informes, cobrindo períodos de cinco anos cada) http://www.coe.int/t/dghl/monitoring/ecri/activities/countrybycountry_en.asp.

${ }^{11}$ Ver, por ex. o relatório em: http://www.coe.int/t/dghl/monitoring/ecri/activities/Statements_ en.asp.
} 
de Direitos Humanos, abrangendo 47 estados europeus e incluindo, por exemplo, Turquia e Rússia, a União Europeia, enquanto coalizão política e econômica de 28 estados membros, desenvolveu seu próprio marco antidiscriminação. Para os propósitos deste artigo, o regime e a política de não discriminação da UE são mais importantes do que aquelas do ConseIho da Europa - em razão do compromisso e da arquitetura institucional mais fortes da EU e dos seus estados membros. Ao longo do tempo, com o desenvolvimento da UE de um esforço econômico de estados independentes para um projeto político-econômico de uma união federativa de estados, as questões de direitos humanos e de não discriminação foram ganhando importância crescente. Em 2000, a UE e seus estados membros promulgaram a Carta de Direitos Fundamentais da União Europeia, a qual reúne as regras básicas de direitos humanos definidas pelos estados membros na Convenção Europeia de Direitos Humanos e as promulgadas nas declarações de direitos humanos vinculadas às Nações Unidas. Inicialmente estabelecida como uma declaração de intenções não vinculante, a carta tornou-se posteriormente obrigatória:

Com a entrada em vigor do Tratado de Lisboa, em 2009, a Carta dos Direitos Fundamentais adquiriu força jurídica vinculativa. Em consequência, as instituições da UE devem obrigatoriamente cumprir as suas disposições. Os Estados-Membros são obrigados, por conseguinte, a respeitar as disposições da Carta, mas apenas em sede de transposição e aplicação da legislação da UE. [...] O artigo 21..$^{\circ}$ da Carta estabelece a proibição da discriminação por vários motivos (FRA, 2010, p.16).

A Corte de Justiça da União Europeia foi estabelecida em 1952. Com o tratado de Lisboa, em 2009, tornou-se a instituição jurídica independente no âmbito da UE, plenamente responsável por assegurar que a legislação da União Europeia seja efetivamente observada. A jurisprudência da Corte de Justiça da UE desempenha um papel relevante ao relacio- 
nar as normas jurídicas formais europeias com a vida prática e suas formas de discriminação. Em geral, a legislação e a política antidiscriminatórias europeias fazem distinção entre discriminação direta e indireta:

pessoas em situações semelhantes devem receber um tratamento semelhante e não ser tratadas de forma menos favorável simplesmente devido a uma determinada característica "protegida" que possuam. O não respeito deste princípio constitui uma discriminação "directa". [...] Em segundo lugar, a legislação antidiscriminação estipula que as pessoas em situações diferentes devem receber um tratamento diferenciado na medida em que isso seja necessário para lhes permitir usufruir de determinadas oportunidades na mesma base que as outras pessoas. Assim, também essas "características protegidas" devem ser tidas em conta quando da execução de determinadas práticas ou ao da criação de determinadas regras. O não respeito deste princípio constitui uma discriminação "indirecta" (FRA, 2010, pp.23-24)

A União Europeia adotou diversas diretivas relacionadas à não-discriminação, as quais deveriam ser transpostas para a legislação nacional de seus estados membros, de modo a constituir um marco legal vinculante relativo à antidiscriminação no âmbito do bloco e de seus estados membros. Em 2000, foram adotadas a Diretiva da Igualdade Racial (Diretiva 2000/43/EC) e a Diretiva da Igualdade no Emprego (Diretiva 2000/78/ EC). Em 2004, a Diretiva de Gênero no acesso a Bens e Serviços (Diretiva 200/13/EC) e a Diretiva de Livre Circulação e Residência de Cidadãos da UE (Diretiva 2004/38/EC) ${ }^{12}$. Todas essas diretivas contêm normas antidiscriminatórias, mas enfatizam diferentes áreas de regulamentação como emprego, acesso à previdência e seguridade social, ou acesso a bens e

\footnotetext{
${ }_{12}$ Para um panorama do complexo quadro legislativo composto de Tratados, Relatórios de Comissões, Diretivas, Documentos de Trabalho, Decisões, Recomendações, Resoluções, Conclusões e Comunicados, ver http://ec.europa.eu/justice/discrimination/law/index_en.htm.
} 
serviços. Essas diretivas abordam uma ampla gama de possíveis formas de discriminação relacionadas a sexo, orientação sexual, deficiências, idade, raça, origem étnica, origem nacional, crença ou religião, língua, origem social, nascimento e riqueza, opinião política ou outra (FRA, 2010, pp. 97129). A par dessa rede relativamente densa de dispositivos legais antidiscriminatórios, existe também uma infraestrutura de organismos específicos.

Além das já mencionadas Corte Europeia de Direitos Humanos e Corte de Justiça da UE, há uma agência de crescente relevância no campo da não discriminação: a Agência dos Direitos Fundamentais da UE, a FRA (Fundamental Rights Agency). Estabelecida em 2007, sucedeu o Observatório Europeu do Racismo e da Xenofobia, com um mandato mais amplo, conforme definido no artigo 2 da Decisão do Conselho de 2008:

Os domínios temáticos são os seguintes: a) racismo, xenofobia e intolerância a eles associada; b) discriminação com base no sexo, na origem racial ou étnica, na religião ou crença, na deficiência, na idade ou na orientação sexual e de pessoas pertencentes a minorias, e qualquer combinação destes motivos (discriminação múltipla); c) compensação das vítimas; d) direitos da criança, incluindo a protecção das crianças; e) asilo, imigração e integração de migrantes; f) vistos e controlo de fronteiras; g) Participação dos cidadãos no funcionamento democrático da União; h) sociedade da informação e, em particular, o respeito pela vida privada e a protecção dos dados pessoais; i) acesso a uma justiça eficiente e independente ${ }^{13}$.

Desde sua fundação, a FRA continuou e ampliou as atividades de monitoramento e de publicação dos resultados através de Relatórios Anuais, informes especiais sobre minorias como o povo roma na Europa, ou

\footnotetext{
13 http://eur-lex.europa.eu/legal-content/EN/TXT/PDF/?uri=CELEX:32008D0203\&from=EN, ver também http://ec.europa.eu/justice/fundamental-rights/document/index_en.htm, acessado em 28.12.20114.
} 
sobre aspectos específicos da discriminação. Há relatórios de surveys representativas sobre questões como violência contra as mulheres, discriminação contra ciganos, antissemitismo na Europa ou discriminação por orientação sexual. A FRA também publica informes específicos e estudos qualitativos sobre países específicos e tem estado cada vez mais interconectada com organizações internacionais e da sociedade civil. Desde 2009, a FRA publica os resultados do levantamento sobre Minorias e Discriminação na União Europeia (EU-MIDIS); a Plataforma dos Direitos Fundamentais compreende mais de trezentas organizações não-governamentais que atuam sobre temas de direitos fundamentais ${ }^{14}$. Afinal, especialmente durante a última década, a luta contra a discriminação tornou-se uma arena característica da União Europeia.

\section{Discriminação na UE - o que é possível saber?}

Embora o marco legal europeu não-discriminatório descrito nas seções anteriores seja impressionante e - de uma perspectiva internacional comparada - inédito, persistem muitas lacunas. Nesta seção, serão abordados apenas alguns aspectos da pesquisa científica e da mensuração da discriminação. Deixaremos de lado todos os demais problemas como tradições políticas nacionais divergentes para lidar com diversidade social e discriminação (ver Pries, 2013a, p.ex.) e a complexa, política e filosoficamente contestada, fronteira entre a proteção a certos grupos e a discriminação de outros grupos (demonstrada, por ex., no contexto das negociações da Diretiva Europeia dos Serviços - Diretiva 2006/123/

\footnotetext{
${ }^{14}$ Ver http://fra.europa.eu/en/publications-and-resources/data-and-maps; http://fra.europa.eu/ en/cooperation/civil-society/participant-organisations; http://fra.europa.eu/en/project/2011/ eu-midis-european-union-minorities-and-discrimination-survey e http://fra.europa.eu/en/ publications-and-resources/country-datat, consultadas em 28.12.2014.
} 
EC - ou da Parceria para Comércio e Investimento Transatlântico - TTIP). Assim, a questão orientadora é: o que de fato sabemos sobre discriminação na União Europeia?

No mesmo ano da criação da FRA, Goodey (2007) discutia os problemas metodológicos para mensurar a violência racista como um aspecto excepcional e relativamente visível da discriminação. Em primeiro lugar, é complicado definir violência racista - e racismo de um modo geral - pois não existe consenso, seja para uma definição jurídico-formal ou para um conceito sociológico preciso e amplamente aceito. Goodey propõe definir violência racista como a violência em que as vítimas são escolhidas não com base em características individuais, mas sim numa estratificação social de grupos minoritários construídos a partir de aspectos fenotípicos, religião, origem nacional ou cultural (ibid: 572). O autor afirma que a definição mais ampla de crime racista é encontrada na Inglaterra e no País de Gales, onde "um incidente racista é qualquer incidente percebido como racista pela vítima ou por qualquer outra pessoa" (ibid: 575). Com relação aos estados membros da UE, o Reino Unido é considerado o único país com um registro adequado sobre violência racista, enquanto em outros países as variáveis raciais são levantadas segundo operacionalizações variadas, ou seu registro é proibido (para a França, ver Wihtol de Wenden et al. 2013). Embora, segundo Goodey, não exista na Europa uma definição operacional consensual para violência racista, desde 2008 vigora uma Decisão Quadro do Conselho da Europa sobre o combate a certas formas e expressões de racismo e xenofobia ${ }^{15}$.

Em vista das distintas fontes de dados sobre a violência racista que no trabalho de Goodey incluem a Rede Europeia contra o Racismo

\footnotetext{
15 Ver: <http://europa.eu/legislation_summaries/justice_freedom_security/combating_discrimination/l33178_en.htm> acessado em 28.12.2014.
} 
(ENAR), a Comissão Europeia contra o Racismo e a Intolerância (ECRI), o Observatório do Racismo e da Xenofobia da UE (EUMC) e sua sucessora, a Agência dos Direitos Fundamentais (FRA) - não há dois estados membros da UE que produzam dados diretamente comparáveis sobre violência racista (ibid: 576). Esta afirmação de Goodey, feita em 2007, é válida ainda, como se pode observar em informe mais recente da FRA (2012, p. 32 e s.) e na nota da página 35 do mesmo, onde todos os estados membros da UE estão ilustrados em uma tabela "Dados oficiais de crimes de ódio publicados em 2010, segundo o motivo do preconceito", cuja nota diz: "Os dados não são comparáveis entre os estados membros da UE" ${ }^{16}$. Segundo Goodey (2007), a comparação direta dos dados entre estados membros do bloco é muito problemática. Alternativamente, dados de um mesmo país podem ser comparados ao longo do tempo e as tendências podem ser analisadas, se não houver mudança nos mecanismos de coleta de dados ao longo do período considerado.

Aplicando este critério aos dados e documentos oficiais de justiça criminal publicados pelo EUMC e pela FRA até agora, Goodey (2007, pp. 580 e s.) afirma que apenas sete dos estados membros da UE produzem dados confiáveis que possibilitam análise de tendências. Oito países apresentaram tendência ascendente de violência racista (Dinamarca, Alemanha, França, Irlanda, Polônia, Eslováquia, Finlândia, e Inglaterra e País de Gales, no Reino Unido); três apresentaram tendência decrescente (República Tcheca, Áustria e Suécia). No entanto, Goodey afirma que essas mudanças deveriam ser analisadas com cautela, uma vez que países com números absolutos baixos, com é o caso de Dinamarca e Irlanda,

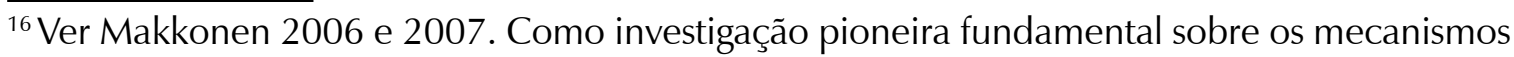
de coleta de dados dos 15 estados membros da UE, tendências dos crimes racistas entre 2001 e 2003 em alguns dos estados membros da UE entre 2001 e 2003, e a situação geral, ver EUMC 2005a e 2005b.
} 
podem sugerir mudanças drásticas com base em valores absolutos bastante baixos. Outro problema mencionado pelo autor é que a qualificação como crime racista com frequência fica limitada a atividades ou grupos proibidos (como na Áustria e na Alemanha, onde contam-se apenas as atividades dos grupos oficialmente designados como de extrema direita).

Nos últimos anos, foram conduzidos diversos estudos para avaliar a qualidade dos dados e encontrar formas de aprimorar o conhecimento sobre discriminação e temas correlatos na UE. Kraler e Reichel (2010) apresentam resultados de um projeto de pesquisa financiado pela $\mathrm{Co}-$ missão Europeia. O estudo compila meta-informação a partir de bases de dados estatísticos sobre migração, integração e discriminação em 29 países europeus (27 da UE e mais Noruega e Suíça). O projeto analisa a comparabilidade das estatísticas europeias relativas à discriminação. Uma vez que seu relatório final discute formas gerais de mensurar a discriminação e armadilhas envolvidas nesses processos, ele será citado de forma mais extensa, a seguir:

É possível mensurar de forma direta a discriminação através do levantamento de incidentes de discriminação denunciados; estatísticas que devem ser levantadas em todos os países da UE. Contudo, essas queixas são avaliadas com base em dispositivos legais e determinar casos individuais é diferente de mensurar a prevalência de discriminação. Outros meios de medir diretamente a discriminação são percepções da discriminação. Tais estatísticas fornecem apenas um quadro rudimentar da existência de discriminação, uma vez que as percepções não necessariamente correspondem à realidade. Vários inquéritos internacionais contêm questões sobre experiências de discriminação. O Eurobarômetro 317 de 2009, por exemplo, continha questões sobre o quanto as pessoas consideram disseminados diferentes tipos de discriminação, sobre a percepção pessoal de ter sofrido discriminação ou assédio e sobre testemunhar incidentes de discriminação contra outros. Até o presente, o mais amplo inquérito de vitimização abordando a discriminação 
Sociologias, Porto Alegre, ano 17, no 40, set/dez 2015, p. 176-211

baseada em origem étnica foi o encomendado pela Agência dos Direitos Fundamentais da UE, denominado Pesquisa sobre Minorias e Discriminação na União Europeia (European Union Minorities and Discrimination Survey - EU MIDIS). Além disso, a propensão para discriminar também pode ser sondada através da coleta de informações sobre determinadas atitudes em relação a imigrantes ou por perguntas diretas sobre se e até que ponto as pessoas se consideram racistas (como no Eurobarômetro 47.1, 1999). No entanto, não se pode presumir um vínculo direto entre posturas e comportamento. Experimentos de campo, como testes de discriminação ou de situação, constituem uma boa fonte para mensuração direta da discriminação. Nesses testes, normalmente, enviam-se dois CVs para uma oferta de emprego. Os CVs são similares, exceto pela origem da pessoa candidata. Consequentemente, diferenças nas respostas aos CVs podem ser diretamente relacionadas à discriminação em razão da origem da pessoa. Embora esses testes tenham sido realizados em vários países europeus, os dados levantados, normalmente não estão disponíveis para análise secundária ${ }^{17}$.

Os problemas de como mensurar a discriminação e de como comparar os respectivos bancos de dados nacionais na UE são discutidos também por Wrench (2011). O autor aborda as deficiências nas práticas de registro de informação nos países da UE, o problema da comparabilidade dos dados sobre discriminação e o uso de métodos quantitativos e/ou qualitativos nas pesquisas envolvendo discriminação racial. Wrench (ibid: 1715) menciona especificamente a pesquisa EU-MIDIS sobre migrantes e minorias, que foi concebida para produzir dados comparáveis. Os países da UE dificilmente produzem estatísticas oficiais sobre discriminação, "em razão de sua natureza altamente contestada" tanto internamente, como entre os países (ibid: 1717). Segundo estudo de 2007, do Conse-

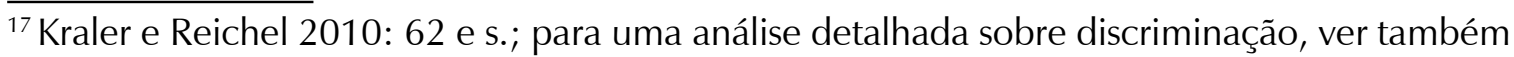
Gächter 2010.
} 
Iho da Europa, 13 dos 27 países da UE contam com a informação "nacionalidade/etnicidade" em suas estatísticas oficiais. Apenas dois estados membros - Irlanda e Reino Unido - registram dados sobre "etnicidade" em seus censos. Portanto, afirma Wrench, na maioria dos países da UE, os dados oficiais pouco contribuem para a identificação dos grupos expostos à discriminação racial. Wrench descreve a evolução dos esforços da UE para combater a discriminação, mencionando a Diretiva da Igualdade Racial, de 2000, o estabelecimento da Agência dos Direitos Fundamentais (FRA), em 2007, e a Rede Europeia sobre Xenofobia e Racismo (Racism and Xenophobia European Network - RAXEN), que consiste de 27 Pontos Focais Nacionais que fornecem dados nacionais.

Segundo Wrench (2011: 1718), esses dados coletados pela RAXEN podem ser objetivos, confiáveis e até mesmo comparativos (no sentido de descrever, analisar e comentar similaridades/diferenças entre os estados membros), mas dificilmente comparáveis, porque não existe um indicador comum de discriminação. O autor menciona ainda, em comparação aos dados da RAXEN baseados em informação (diferente) específica de cada país, a estratégia da FRA como uma alternativa: produzir dados genuínos e comparáveis no âmbito da Europa, com base na implementação de pesquisas sobre discriminação que utilizam a mesma metodologia em todos os estados membros. Nessa linha, um estudo do Observatório Europeu do Racismo e da Xenofobia (EUMC) analisou dados do Eurobarômetro e da Pesquisa Social Europeia sobre atitudes da maioria de cada país em relação às minorias (EUMC 2005) $)^{18}$. A FRA desenvolveu seu projeto

\footnotetext{
${ }^{18} \mathrm{O}$ Eurobarômetro é uma amostra representativa de 1.000 pessoas na maioria dos estados membros da UE. Incluía duas declarações relacionadas à discriminação ("É bom para qualquer sociedade ser constituída de pessoas de diferentes raças, religiões e culturas" e "Há um limite para o número de pessoas de outras raças, religiões e culturas que uma sociedade pode aceitar") às quais os entrevistados poderiam expressar sua concordância ou oposição. A Pesquisa Social Europeia (ESS) envolve amostras representativas de 1.500 a 2.500 pessoas na maioria dos estados membros da UE. Três declarações relacionadas à distância étnica (Você se
} 
EU-MIDIS, que pesquisa as experiências de migrantes e de minorias com discriminação, crimes racistas e policiamento ${ }^{19}$.

Segundo Wrench (2011, p. 1719 e s.), a Pesquisa Social Europeia (utilizada no relatório da FRA) inclui um número insignificante de migrantes e de pessoas pertencentes a minorias. $\mathrm{O}$ autor sugere como fontes alternativas as queixas registradas pelas vítimas (tanto na polícia quanto junto a ONGs), mas admite (assim como muitos outros pesquisadores) que a maior parte desses casos não é notificada. Apesar de reconhecer a pesquisa EU-MIDIS como o único estudo sobre grupos minoritários que utilizou de forma sistemática o mesmo questionário padrão em todos os estados membros da UE, possibilitando, portanto, a comparação entre grupos minoritários de todos esses países, Wrench formula uma crítica geral: "Métodos quantitativos são intrinsecamente menos úteis do que os qualitativos quando se trata de captar a realidade a discriminação" (ibid: 1725), em razão da subjetividade envolvida na percepção da discriminação e por ser um tema por demais sensível para um questionário formal. Assim, segundo Wrench, o desejo de comparabilidade não deve levar a negligenciar a pesquisa social qualitativa, pois esta pode contribuir para a compreensão dos processos de discriminação e racismo. Portanto, em geral, é aconselhável uma combinação de métodos de pesquisa (ibid: 1728).

\footnotetext{
importaria se seu chefe fosse um imigrante da mesma raça/ grupo étnico da maioria? Você se importaria se um parente próximo casasse com uma pessoa imigrante da mesma raça/origem étnica da maioria? Você se importaria se seu chefe fosse um imigrante de uma raça/origem étnica diferente da maioria?

${ }^{19}$ Para a última ver: http://fra.europa.eu/en/project/2011/eu-midis-european-union-minorities-and-discrimination-survey.
} 


\section{Situação atual do racismo e da discriminação na UE}

Para discutir os estudos atuais mais abrangentes sobre racismo na UE, deve-se começar com a Pesquisa de Minorias e Discriminação da União Europeia (EU-MIDIS), como também observou Wrench (2011: 1723). Nessa pesquisa, a FRA, através de amostragem aleatória e de um questionário padronizado, entrevistou 23.500 pessoas de várias minorias étnicas e diferentes grupos de imigrantes, em todos os estados membros da UE (no máximo três grupos por país com uma amostra de no mínimo 500 respondentes para cada grupo), questionando sobre experiências de discriminação vivenciadas em 2008 (FRA, 2009). Os grupos ${ }^{20}$ foram selecionados com base em dois critérios: constituir o maior grupo minoritário do país e estar potencialmente vulnerável à discriminação ${ }^{21}$. Consequentemente, as comparações foram feitas entre os estados membros em relação aos mesmos grupos minoritários ${ }^{22}$. Uma pesquisa suplementar com a população majoritária foi conduzida em dez estados membros, envolvendo uma amostra total de 5.068 pessoas, para comparação com os resultados da pesquisa principal. Em vista disso, a EU-MIDIS constitui a mais abrangente pesquisa sobre experiências de racismo e discriminação por parte de minorias em toda a UE (FRA, 2009: 6-27).

\footnotetext{
${ }^{20}$ Para a lista de todas as minorias selecionadas no âmbito dos estados membros, ver Tabela 1.5 „EU-MIDIS Sample Sizes“ do relatório EU-MIDIS Main results report (principais resultados) (FRA 2012:27)

21 “...a seleção dos grupos para amostragem foi orientada pelos relatórios nacionais anuais sobre a situação do racismo e da xenofobia em cada estado membro, os quais foram submetidos à agência e seu predecessor, o EUMC, a partir de 2000, por sua rede RAXEN de pontos focais nacionais (dos quais há um em cada estado membro). Os resultados desta coleta de dados estão publicados pela agência em seu relatório anual, que examina a situação do racismo e da xenofobia nos estados membros da UE " (FRA 2009: 22).

${ }^{22}$ Para comparações detalhadas ver relatórios especiais; por ex. FRA 2012a para as experiências de roma em sete estados membros.
} 
Em toda a União Europeia, o mais alto grau de discriminação étnica na vida cotidiana foi indicado pela população roma: metade dos respondentes roma experimentou tratamento discriminatório pelo menos uma vez ao longo dos doze meses anteriores à pesquisa. Outros grupos minoritários fortemente discriminados foram: os africanos subsaarianos (41\%), os norte-africanos (36\%) e entrevistados de descendência turca, da Europa Central e da Europa Oriental (23\%). Com relação a dados específicos por país, os mais elevados graus de discriminação foram identificados em relação aos roma na República Tcheca (64\%), aos africanos em Malta (63\%), aos roma na Hungria (62\%), aos roma na Polônia (59\%) e aos roma na Grécia (55\%; ibid: 8). Em 2008, os roma, mais do que qualquer grupo étnico na EU, sofreram discriminação em todas as esferas da vida cotidiana. Além disso, um grau preocupante de vitimização entre a população roma foi destacado pelo Relatório Resumido da Pesquisa: Minorities as victims of crime (Minorias como vítimas do crime) (FRA, 2012a) ${ }^{23}$. Neste relatório, os respondentes foram questionados especificamente sobre terem experimentado algum crime de ódio, se poderiam identificar de alguma forma o motivo, o perpetrador etc.

Alguns dos achados mais surpreendentes foram: 18\% de todas as pessoas entrevistadas descendentes de roma ou de africanos subsaarianos indicaram terem sido vítimas de um crime de motivação "racista" pelo menos uma vez nos doze meses anteriores à pesquisa, o que constitui o dado mais elevado em toda a UE. Os maiores índices para esses crimes entre os estados membros foram documentados nos casos da população roma na República Tcheca e dos somalis na Finlândia (ambos 32\%; ver

\footnotetext{
${ }^{23}$ Para os problemas metodológicos em geral, ver FRA 2012b; o estudo fornece um apanhado geral dos mecanismos de coleta de dados oficiais relativos a crimes de ódio pelos estados membros da UE e publica uma tabela com os dados oficiais disponíveis, concluindo que esses não são comparáveis entre os estados membros.
} 
FRA, 2012a : 11). Quase um sexto de todos os subsaarianos e roma consideraram que linguagem "racista" ou ofensiva à sua religião foi utilizada durante um ataque, uma ameaça ou um assédio grave (ibid: 12). Apenas $13 \%$ dos respondentes de origem turca e $12 \%$ dos roma (esses são os dados mais altos de toda a UE) indicaram que os perpetradores eram membros de gangues racistas ou de extrema-direita. Isso significa que os demais crimes de motivação racista foram perpetrados aparentemente por "cidadãos comuns" (ibid: 13). Apesar disso, mesmo os crimes qualificados como graves não foram denunciados à polícia pela maior parte das vítimas (ibid: 14).

A EU-MIDIS, como a primeira e única pesquisa sobre grupos minoritários que utiliza o mesmo questionário para toda a UE, de fato propicia resultados efetivamente comparáveis. No entanto, deve-se ter em mente que os resultados devem ser comparados ou entre os mesmos grupos minoritários, se esses estiverem igualmente presentes em vários países ${ }^{24}$, ou entre grupos minoritários distintos no âmbito do mesmo estado membro (FRA 2009: 20). Além disso, o relatório recebeu críticas, dizendo que seus resultados devem ser interpretados e utilizados com cautela. Infelizmente, uma pesquisa com esse escopo, por definição, é portadora dessa fragilidade, já que, em razão das diferenças de legislação entre os países da UE, é quase impossível verificar que, de fato, um incidente se qualifique como crime de ódio. Apesar disso, o relatório ainda utiliza termos como "vitimização" e "vítima de crime" sem o adjetivo "suposta". Os autores argumentam que, ao expressarem-se desse modo, apenas seguem a prática estabelecida na língua inglesa para discutir os resultados dos surveys sobre vitimização criminal (FRA, 2012a: 7). A segunda etapa da EU-MIDIS, com um programa extra "Estratégias de Integração da População Roma" será

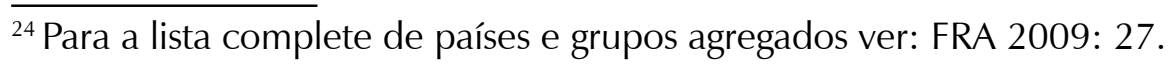


realizada em 2015 e seus primeiros relatórios serão publicados no segundo semestre de $2016^{25}$.

Em 2013, a Agência de Direitos Fundamentais (FRA) publicou, pela primeira vez na história, um relatório sobre antissemitismo nos estados membros da UE. Oito países (Bélgica, França, Alemanha, Hungria, Itália, Letônia, Suécia e Reino Unido) participaram do relatório que conclui: “Dois terços dos respondentes da pesquisa (66\%) consideram o antissemitismo como um problema nos oito estados membros da UE pesquisados, enquanto, em média, três quartos dos respondentes (76\%) também acreditam que a situação agravou-se e que o antissemitismo cresceu no país onde vivem, ao longo dos últimos cinco anos" (FRA 2013: 11). O antissemitismo na internet foi indicado como o maior problema (ibid.: 18). Um terço de todos os respondentes afirmou ter experimentado pessoalmente vexames antissemitas (ibid.: 44).

Outra fonte de dados importante sobre a situação atual em termos de discriminação e racismo na Europa (esta não quantitativa, mas qualitativa) é propiciada pela Rede Europeia contra o Racismo (European Network Against Racism - ENAR), especialmente em seus chamados "Relatórios Sombra" ${ }^{26}$. Em 2014, a ENAR publicou um Relatório Especial sobre racismo e discriminação no emprego na Europa (Lamberts et al., 2014). Sendo a única rede pan-europeia de ONGs que atuam em conjunto para investigar e combater o racismo na Europa, a ENAR publica também, anualmente, "Relatórios Sombra" específicos por país para os estados mem-

\footnotetext{
${ }^{25}$ Ver http://fra.europa.eu/en/project/2015/eu-midis-ii-european-union-minorities-and-discrimination-survey.

${ }^{26}$ Os relatórios sombra da ENAR são produzidos anualmente como uma compilação dos dados coletados pelas organizações não governamentais filiadas à rede "para preencher as lacunas dos dados oficiais e acadêmicos, oferecer uma alternativa a esses dados, e para oferecer a perspectiva das ONGs sobre as realidades do racismo na UE e em seus estados membros" (para mais informação acessar: http://www.enar-eu.org/Shadow-Reports-on-racism-in-Europe-203).
} 
bros da UE (23 estados membros da UE, mais a Turquia, em 2014) ${ }^{27}$. Embora enfatizando a não comparabilidade dos resultados, eles identificam uma tendência comum para o mercado de trabalho em 2014, na Europa: os imigrantes de países não integrantes da UE, refugiados e solicitantes de asilo, muçulmanos, roma e travellers ${ }^{*}$, pessoas negras, e especialmente todas as mulheres pertencentes a um desses grupos (como consequência da múltipla discriminação) são identificados como os grupos mais vulneráveis à discriminação no emprego (Lamberts et al., 2014: 29).

Além disso, dependendo das motivações da discriminação, os autores concluem que os roma e os travellers têm sido sistematicamente vitimizados em razão de sua etnicidade, e sofrem muito mais discriminação no mercado de trabalho do que outros grupos étnicos. Com relação aos povos roma, as piores condições para entrada no mercado de trabalho foram encontradas em "Relatórios Sombra" da Áustria, Bélgica, Bulgária, Croácia, República Tcheca e Finlândia (Lamberts et al., 2014, p. 30). Os muçulmanos são caracterizados como o grupo mais vulnerável à discriminação de ordem religiosa ou de crença em praticamente todos os estados membros (o que é evidenciado nos "Relatórios Sombra" da Áustria, Bélgica, Bulgária, Croácia, República Tcheca, Finlândia, França, Alemanha, Grécia, Itália, Lituânia, Luxemburgo, Holanda, Polônia, Espanha, Reino Unido e, mesmo, Turquia). Mais do que isso, conforme apontam Lamberts et al (2014), a experiência de qualquer mulher muçulmana na Alemanha fornece um exemplo claro da mais severa discriminação no trabalho, em razão da múltipla discriminação: "Uma mulher muçulmana, de origem imigrante e que

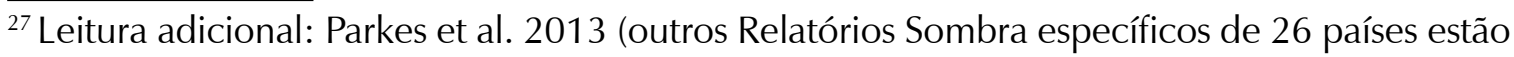
disponíveis); Gauci 2012 (Relatórios Sombra específicos de 27 países estão disponíveis); Gauci2011 (Relatórios Sombra específicos de 27 países estão disponíveis)

* Um grupo nômade parecido com os roma, encontrado principalmente na Irlanda e no Reino Unido [Nota do organizador].
} 
cobre a cabeça com o hijab é [...] uma mulher que incorpora três grandes barreiras que impedem seu acesso ao mercado de trabalho" (ibid: 31 ).

O Eurobarômetro ${ }^{28}$, como terceira fonte de dados sobre discriminação na Europa, é visto como um reflexo dos valores, percepções e opiniões dos cidadãos. Baseado em uma amostra representativa de 1.000 pessoas na maioria dos países da UE, o Eurobarômetro 2012 fornece dados valiosos sobre a discriminação na Europa em geral (European Commission, 2012). Além disso, permite identificar algumas tendências ao longo de três anos, 2009 a 2012. Especificamente, a discriminação com base na origem étnica ainda é percebida como a forma mais disseminada de discriminação na UE, embora tenha havido uma pequena melhora em comparação com 2009 (56\% dos europeus pensam que é um problema, contra os $61 \%$ de 2009). Seguem-se a essa a discriminação baseada nas deficiências (53\%) e na orientação sexual (46\%). A discriminação baseada na religião ainda é bastante disseminada (39\%), e a mudança mais sensível entre oito motivações de discriminação é percebida na categoria gênero (de 40\% em 2009, para 31\% em 2012; European Commission, 2012, p. 16).

No entanto, a percepção nacional dos níveis de discriminação difere consideravelmente entre os estados membros. Por exemplo, enquanto mais de 70\% dos cidadãos e cidadãs de França, Chipre, Suécia, Grécia, Holanda, Dinamarca e Hungria acreditam que a discriminação por origem étnica é comum em seus respectivos países, apenas 17\% dos lituanos ou $26 \%$ dos poloneses e dos letões pensam o mesmo. A Alemanha, com

\footnotetext{
${ }^{28} \mathrm{O}$ Eurobarômetro é uma série de pesquisas de opinião pública conduzidas pela Comissão Europeia nos estados membros desde 1973. Elas abordam os principais temas e áreas relacionadas à cidadania europeia, tais como saúde, cultura, meio ambiente etc. (para mais informações, visite: http://ec.europa.eu/public_opinion/index_en.htm). Este artigo fornece um panorama do Special Eurobarometer 393, Discrimination in the EU in 2012.
} 
seus 51\%, fica a meio caminho (European Commission, 2012, p. 29). A melhoria mais notável parece estar em Malta (com um aumento de 23\% nos respondentes afirmando que discriminação é rara ou inexistente em seu país). Na Alemanha, em 2012, três por cento a mais (45\%) do que em 2009 (42\%) responderam que a discriminação por origem étnica era rara ou inexistente (ibid: 29 e s.). Em 2012, a média dos respondentes da UE que consideravam a discriminação com base em origem étnica como sendo rara ou inexistente foi de $39 \%$ e havia melhorado em $4 \%$.

$\mathrm{Na}$ UE como um todo, a discriminação com base em crenças ou religião é com mais frequência considerada rara ou inexistente (56\%) do que comum (39\%). A França lidera o ranking, com uma maioria de 66\% dos entrevistados acreditando que a discriminação baseada em religião ou crenças é comum; com relação a essa questão, apenas 34\% na Alemanha responderam 'Comum' (European Commission, 2012, p. 49). O relatório dedica atenção especial ao povo roma: três quartos de todos os entrevistados europeus concordam que os roma como grupo social estão sob risco de discriminação (ibid, p. 111). O Eurobarômetro 2012 traz uma interessante consideração final que relaciona o grau de percepção de discriminação aos tipos de pertencimento social autoatribuídos e à variedade de redes sociais:

Em geral, a autoidentificação como pertencente a um grupo minoritário aumenta a probabilidade de o respondente acreditar que a discriminação (inclusive, mas não exclusivamente contra esse grupo específico) seja comum em seu país. Os respondentes que dizem pertencer a uma minoria são também mais tendentes do que a média dos europeus a informar que vivenciaram pessoalmente episódios de discriminação. O grau de diversidade do círculo social de um respondente tem uma influência marcante sobre sua consciência da discriminação, assim como sobre o quão confortável ele ou ela se sente em relação às minorias (European Commission, 2012, p. 119). 
É interessante observar que a percepção do grau de diversidade na Europa é bastante alta e vem crescendo. Com relação à religião, 67\% dos entrevistados responderam ter amigos ou conhecidos com outra religião ou crença diferente da sua (três por cento mais alta do que em 2009); $62 \%$ responderam ter amigos ou conhecidos portadores de deficiências (quatro por cento mais do que em 2009); 59\% indicaram ter amigos ou conhecidos de diferentes origens étnicas (dois por cento mais do que em 2009). O índice para amigos ou conhecidos com orientação sexual diferente (gays, lésbicas ou bissexuais) continua mais baixo, em $41 \%$, e apenas $18 \%$ indicaram ter amigos ou conhecidos roma ( $1 \%$ mais do que em 2009). "Outro avanço é que mais europeus hoje sentem-se tranquilos com a ideia de que uma pessoa dentre os grupos minoritários mencionados venha a comandar seu país" (European Commission, 2012, p. 120).

\section{Conclusão: tendências e desafios para novas pesquisas}

Com relação a questões de não discriminação, algumas tendências gerais podem ser observadas na UE. Em primeiro lugar, há uma clara tendência em direção a uma melhoria nos requisitos formais de não-discriminação no âmbito da União Europeia e de seus estados membros, no sentido de uma ampliação e aprofundamento das normas e definições. Em segundo lugar, iniciativas legais surgidas em uma determinada área de ação política e de regulamentação institucional (como emprego ou livre comércio de bens e serviços) contendo dispositivos mínimos antidiscriminatórios, entrelaçam-se, indiretamente, cada vez mais, por referência a outras Diretivas, Comunicações etc. E também, diretamente, ao serem incorporadas a novas iniciativas legislativas especiais - como a Comunicação de Não-Discriminação e Oportunidades Iguais: um compromisso 
renovado (SEC/2008/2172 ${ }^{29}$ ) e a relacionada Proposta para uma Diretiva do Conselho sobre a implementação do princípio de igual tratamento entre pessoas, independentemente de religião ou crença, deficiência, idade ou orientação sexual (SEC/2008/2180 ${ }^{30}$ e SEC/2008/218131). Em terceiro lugar, com base no arcabouço legal, uma arena europeia de atores coletivos está fortalecendo-se; um regime de não-discriminação torna-se cada vez mais institucionalizado na Europa por meio de um fortalecimento mútuo de meios legais-formais e de redes funcionais de atores, bem como de um complexo jogo de ping-pong entre os âmbitos nacional, europeu, internacional e transnacional.

A história europeia e, particularmente, o caso da Alemanha ensina que a discriminação e o racismo não devem ser negligenciados. E, todavia, a discriminação em todas as esferas da vida - e o racismo como uma forma ameaçadora daquela - é uma dura realidade nas vidas de imigrantes e de minorias étnicas ou religiosas na Europa. Embora os roma constituam a mais numerosa minoria étnica da Europa, isso não os impede de sofrerem discriminação, exclusão social e, mesmo, marginalização, de forma cotidiana, a despeito de a maioria ter a cidadania europeia ${ }^{32}$. Além disso, em muitos estados membros, os roma, assim como os africanos subsaarianos, são recorrentemente associadas a atividades criminosas. No entanto, o EU-MIDIS mostra claramente que ambos os grupos são, antes, vítimas de crimes de motivação racial. De fato, os grupos étnicos minoritários têm atraído crescente interesse em estudos abrangentes sobre racismo, discutidos neste artigo, devido ao entendimento entre grupos de

\footnotetext{
${ }^{29}$ Disponível em: < http://www.ipex.eu/IPEXL-WEB/dossier/document/SEC20082172FIN.do> ${ }^{30}$ Disponível em: < http://eur-lex.europa.eu/legal-content/EN/XT/?uri=CELEX:52008SC2180> ${ }^{31}$ Disponívelem: < http://eur-lex.europa.eu/legal-content/ENALL/?uri=CELEX:52008SC2181> ${ }^{32}$ A população estimada de roma na Europa é de 10 a 12 milhões (FRA 2009:107).
} 
especialistas, de políticos e do público em geral de que a discriminação não deve ser tolerada e, portanto, deve ser criteriosamente estudada.

Infelizmente, sabe-se ainda muito pouco sobre a verdadeira extensão das práticas discriminatórias na União Europeia. Segundo Wrench (2011: 1716), não existe um sistema modelo de coleta de dados que permita documentar as manifestações de discriminação e racismo em qualquer estado membro da UE com base em definições e indicadores comparáveis e consensuais. Consequentemente, apesar de todos os esforços desenvolvidos pelas instituições e organizações descritas nas seções anteriores, ainda resta muito por fazer nos âmbitos governamental, científico e de ativistas não-governamentais, para combater a discriminação. A ideia de uma "Área de Liberdade, Segurança e Justiça" europeia é simpática e atrativa, mas precisa ser desenvolvida e posta em prática. As manifestações do PEGIDA em Dresden, que portaram fortes elementos discriminatórios e racistas e reuniram mais de dez mil pessoas, duraram apenas cerca de três meses. Mas, como escreveu o poeta e dramaturgo alemão, Bertolt Brecht, em sua peça $A$ resistível ascensão de Arturo Ui: "Ainda é fértil o ventre em que ele foi gerado". A todavia forte e, em alguns países, crescente influência dos partidos nacionalistas de extrema direita, anti-islâmicos e antissemitas assim como os recentes eventos em diversos países da Europa demonstram que a discriminação e o racismo seguem sendo um sério desafio - tanto para a sociedade civil como para cientistas.

Ludger Pries é Doutor em Ciências Sociais e Professor Catedrático de Sociologia/Organização, Migração, Participação na Ruhr-Universität Bochum, Alemanha. $\triangle$ Ludger.Pries@rub.de

Natalia Bekassow é aluna de mestrado em Ciências Sociais na Ruhr-Universität Bochum, Alemanha e Ajudante de Pesquisa da Cátedra Sociologia/Organização/ Migração, Participação nessa mesma universidade. \natalia.bekassow@rub.de 
Sociologias, Porto Alegre, ano 17, no 40, set/dez 2015, p. 176-211

\section{Referências}

1. BAMF (Bundesamt für Migration und Flüchtlinge). Migrationsbericht 2013. Nürnberg: BAMF, 2015. Disponível em: http://www.bamf.de/SharedDocs/Anlagen/DE/Publikationen/Migrationsberichte/migrationsbericht-2013.html

2. ELIAS, Norbert; SCOTTSON, John, L. The Established and the Outsiders. A Sociological Enquiry into Community Problems. London: Frank Cass \& Co, 1965.

3. EUMC (European Monitoring Centre on Racism and Xenophobia). Majorities' Attitudes Towards Minorities: Key Findings from the Eurobarometer and the European Social Survey. Vienna: EUMC, 2005a

4. EUMC (European Monitoring Centre on Racism and Xenophobia). Racist Violence in 15 EU Member States. A Comparative Overview of Findings from the RAXEN National Focal Points Reports 2001-2004. EUMC, 2005b. Disponível em: http://fra.europa.eu/sites/default/files/fra_uploads/190-CS-RV-main.pdf. Acessoem 28.12.2014

5. European Commission. Discrimination in the EU in 2012. Special Eurobarometer 393. Brussels: European Commission, 2012.

6. FRA (European Union Agency for Fundamental Rights), EU-MIDIS. European Union Minorities and Discrimination Survey. Main Results Report. Vienna: FRA. DOI: 10.2811/32815, 2009.

7. FRA (European Union Agency for Fundamental Rights). Handbook on European non-discrimination law. Luxembourg: Publications Office of the European Union, 2010.

8. FRA (European Union Agency for Fundamental Rights). EU-MIDIS Data in Focus Report. Minorities as victims of crime. Luxemburg: Publications Office of the European Union, 2012a.

9. FRA (European Union Agency for Fundamental Rights). Making hate crime visible in the European Union: acknowledging victims' rights. Luxembourg: Publications Office of the European Union, 2012b.

10. FRA (European Union Agency for Fundamental Rights). Discrimination and hate crime against Jews in EU Member States: experiences and perceptionsof anti-Semitism. Luxembourg: Publications Office of the European Union, 2013.

11. G $\ddot{A C H T E R, ~ A u g u s t . ~ D a t a ~ n e e d s ~ a n d ~ d a t a ~ a v a i l a b i l i t y ~ f o r ~ d i s c r i m i n a t i o n ~ r e-~}$ search in Europe. Working Paper No. 10, PROMINSTAT, 2010. Vienna: ICMPD. Disponível em: <http://research.icmpd.org/fileadmin/ResearchWebsite/Project_ material/PROMINSTAT_File_Exchange/Working_Paper_10_Discrimination.pdf $>$. Acesso em 29.12.2014 
12. GAUCI, Jean-Pierre. Racism in Europe: ENAR Shadow Report 2010-2011. Brussels: ENAR, 2011.

13. GÖKTÜRK, Deniz el al. Transit Deutschland. Debatten zu Nation und Migration. Eine Dokumentation. Konstanz: Konstanz University Press, 2011.

14. GOODEY, Jo. Racist violence in Europe. Challenges for official data collection. In: Ethnic and Racial Studies,v. 30, n.4 July 2007, pp. 570-589.

15. GOSEWINKEL, Dieter. Einbürgern und Ausschließen. Göttingen: Vandenhoeck\& Ruprecht, 2001.

16. GOSEWINKEL, Dieter. Politische Kultur im Wandel von Staatlichkeit. Berlin: Sigma, 2007.

17. JAHR, Christoph. Antisemitismus vor Gericht. Debatten über die juristische Ahndung judenfeindlicher Agitation in Deutschland (1879-1960). Wissenschaftliche Reihe des Fritz Bauer Instituts, Bd. 16. Frankfurt a. M. : Campus, 2011.

18. KRALER, Albert; REICHEL, David. Statistics on Migration, Integration and Discrimination in Europe. PROMINSTAT Final Report. Vienna, 2010: ICMPD. Disponível em: <http://research.icmpd.org/fileadmin/ResearchWebsite/Project_material/PROMINSTAT_File_Exchange/PROMINSTAT_FINAL_REPORT.pdf > Acesso em 29.12.2014

19. LAMBERTS, Miet; ODE, Arend; WITKAMP, Bertine. Racism and discrimination in employment in Europe: ENAR Shadow Report. Brussels: ENAR, 2014.

20. LAMONT, Michèle; MIZRACHI, Nissim. Ordinary people doing extraordinary things: responses to stigmatization in comparative perspective. In: Ethnic and Racial Studies, v. 35, n.3, 2012, pp. 365-381.

21. LENTIN, Alana. Racism \& Anti-Racism in Europe. London: Pluto Press, 2004.

22. MAKKONEN, Timo. Measuring Discrimination: Data collection and EU Equality Law. Luxemburg: Office for Official Publications of the European Communities, 2006.

23. MAKKONEN, Timo. European Handbook on Equality Data: Why and How to Build a National Knowledge based on Equality and Discrimination on the Grounds of Racial and Ethnic Origin, Religion and Belief, Disability, Age and Sexual Orientation, Luxemburg: Office for Official Publications of the European Communities, 2007.

24. MÜLLER, Marion. "The evils of racism and the wealth of diversity" - Zum Bedeutungswandel der Rassenkategorie bei den UN-Weltkonferenzen gegen Rassismus. In: Zeitschrift für Soziologie, v. 43, n.6, 2014, pp. 402-420. 
Sociologias, Porto Alegre, ano 17, no 40, set/dez 2015, p. 176-211

25. $M U ̈ N C H$, Ingo von. Die deutsche Staatsangehörigkeit. Vergangenheit- Gegenwart- Zukunft. Berlin: de Gruyter, 2007.

26. PARKES, Brenda et al. Racism in Europe: ENAR Shadow Report 2011-2012. Brussels: ENAR, 2013.

27. PRIES, Ludger (ed.). Shifting boundaries of belonging. New migration dynamics in Europe and China. Houndmills: Palgrave, 2013a.

28. PRIES, Ludger. Changing Categories and the Bumpy Road to Recognition in Germany. In: PRIES, Ludger (ed.) Shifting boundaries of belonging. New migration dynamics in Europe and China. Houndmills: Palgrave, pp. 55-85, $2013 \mathrm{~b}$.

29. PRIES, Ludger. Soziologie. Schlüsselbegriffe, Herangehensweisen und Perspektiven. Weinheim: Beltz-Juventa, 2014.

30. WIHTOL DE WENDEN, Catherine; SALZBRUNN, Monika; WEBER, Serge. Beyond Assimilation: Shifting Boundaries of Belonging in France. In: PRIES, Ludger (Ed.), Shifting boundaries of belonging. New migration dynamics in Europe and China. Houndsmills: Palgrave, pp. 26-54, 2013.

31. WEISS, Anja. Rassismus wider Willen. Ein anderer Blick auf eine Struktur sozialer Ungleichheit (2nd edition). Wiesbaden: VS Springer, 2013.

32. WRENCH, John. Data on discrimination in EU countries: statistics, research and the drive for comparability. In: Ethnic and Racial Studies, v.34, n.10 October 2011, pp. 1715-1730.

Recebido em: 27/03/2015

Aceite final em: 21/05/2015 